Original Research

\title{
Photocatalytic Degradation of Synthetic Organic Reactive Dye Wastewater Using GO-TiO Nanocomposite
}

\author{
Vetriselvan Kumaran ${ }^{1 *}$, Sudhagar P1, Ajay Kumar Konga ${ }^{2}$, Gomathipriya Ponniah ${ }^{1}$ \\ ${ }^{1}$ Effluent Treatment Laboratory, Chemical Engineering, A.C. Tech, Anna University, Chennai, India \\ ${ }^{2}$ Department of Chemical Engineering, Adhiyamaan College of Engineering, Hosur, India
}

Received: 27 February 2019

Accepted: 28 April 2019

\begin{abstract}
One of the major sources of organic pollution is textile dyes, which are also considered toxic and carcinogenic. Among these dyes, azo is one of the main hazardous dyes that cause skin problems and tumors. To remove these organic pollutants, conventional methods such us physicochemical, biological and mechanical treatments are employed currently. Photocatalysis, one of the latest physio-chemical methods for the removal of organic pollutants from effluents, is employed in this study. The present work focuses on the synthesis of graphene oxide (GO) using modified Hummer's method. This is followed by preparation of nanocomposite catalyst $\mathrm{GO}$ - titanium dioxide $\left(\mathrm{TiO}_{2}\right)$ using the ultra-sonication method. $\mathrm{GO}$ and $\mathrm{GO}-\mathrm{TiO}_{2}$ nanocomposite was characterized by X-ray diffractometry (XRD), Fourier transform infrared spectroscopy (FTIR) and scanning electron microscopy (SEM/HRSEM). The prepared nanocomposite was used as a catalyst in photocatalysis to treat dye-affected wastewater. The effect of time, dye concentration, catalyst dosage, and $\mathrm{pH}$ were studied for the removal of orange ME2RL by photocatalysis using synthesized $\mathrm{GO}-\mathrm{TiO}_{2}$, and the experiments revealed significant degradation of orange ME2RL dye. The catalyst was examined for recyclability five times and the results found for the $1^{\text {st }}, 2^{\text {nd }}, 3^{\text {rd }}, 4^{\text {th }}$ and $5^{\text {th }}$ studies were $99.6,99.2,98.8,98.3$ and 98 percentages, respectively. The results show the possibility of using $\mathrm{GO}_{-} \mathrm{TiO}_{2}$ nanocomposite for the effective treatment of organic azo dyeaffected water by photocatalysis.
\end{abstract}

Keywords: preparation of $\mathrm{GO}^{-\mathrm{TiO}_{2}}$ nanocomposites, removal of orange ME2RL, photocatalysis of reactive dye, reusability of $\mathrm{GO}-\mathrm{TiO}_{2}$ nanocomposites, treatment of dye-affected water

\section{Introduction}

Most of the organic dyes used in textile industries are highly carcinogenic. $25-35 \%$ of these dyes get

*e-mail: vetriselvan@annauniv.edu consumed during the textile dyeing process and the remaining portion of the dye is directly discharged into different environmental components as aqueous effluent. It is widely known that some azo dyes and degradation products such as benzidine, naphthalene, etc., released from textile industries cause severe health and environmental hazards [1]. 
Many commercial azo dyes have stability greater than $2000 \mathrm{hrs}$ in sunlight energy [1, 2]. Due to this high stability and high percentage of concentration, conventional methods are not sufficient in the degradation of reactive dyes, and it is difficult to remove these dyes from the water by conventional processes such as direct precipitation, separation, adsorption, etc. Also, these techniques are non-destructive, since they only convert the nonbiodegradable matter into sludge, giving rise to a new type of pollution needing a further treatment step [3]. These difficulties have led to the study of other effective methods. In the latest research articles, it has been suggested to employ photocatalytic degradation using a semiconductor catalyst. Heterogeneous photocatalysis is a very good alternative for purification of dye-containing wastewater. It is also cost-effective [4].

A photocatalyst is a substance which can modify the rate of chemical reaction using light irradiation. A wide array of photocatalysts is available for the degradation of undesirable environmental pollutants. Out of them, more studies have suggested that titanium dioxide and zinc oxide catalysts were most effective for the degradation of an organic pollutant under UV radiation $[2,5] . \mathrm{TiO}_{2}$ is a semiconductor material with a desirable band gap, which shows good catalytic activity to degrade organic pollutants. $\mathrm{TiO}_{2}$ catalyst is used in air purification, wastewater treatment and hydrogen or oxygen conversions due to its high photosensitivity, chemical stability, desirable bandgap, strong oxidizing power, and low cost $[1,6]$. $\mathrm{TiO}_{2}$ also has some disadvantages like low response under visible light due to its short absorptive wavelength, a high rate of recombination of the photoinduced electronhole pair and low utilization rate $[2,5,7]$.

Graphene oxide (GO) is the best promoter for a $\mathrm{TiO}_{2}$-based photocatalyst and is considered a promising material for different applications owing to its excellent properties like aqueous processability, amphiphilicity, surface functionalizing ability, surface-enhanced Raman scattering and fluorescence quenching ability [8-11]. GO contains a range of reactive oxygen functional groups, making it suitable for forming a hydrogen bond or Van der Waals force with $\mathrm{TiO}_{2}$, and to create a wide number of electron-hole pair recombinations. Thermal treatment of GO can restore its electrical conductivity. Also, it increases photocatalytic activity [12-14].

In this work, the focus is given on using thermally treated GO to reduce the demerits of $\mathrm{TiO}_{2}$ and to improve its photocatalytic ability so as to achieve higher rates of removal of organic reactive dye from wastewater.

\section{Material and Methods}

\section{Chemicals Required}

Chemicals used for the experiment were graphite powder $\left(60\right.$ mesh), sulfuric acid $\left(\mathrm{H}_{2} \mathrm{SO}_{4}\right)$, potassium permanganate $\left(\mathrm{KMnO}_{4}\right)$, hydrogen peroxide (of $30 \%$ purity), sodium nitrate $\left(\mathrm{NaNO}_{3}\right)$, titanium di-oxide $\left(\mathrm{TiO}_{2}\right)$ and ethanol $\left(\mathrm{C}_{2} \mathrm{H}_{5} \mathrm{OH}\right)$. The required dyes and chemicals were purchased from K.M.P Dyes and Chemicals, Tirupur. All chemicals are of analytical reagent $(A R)$ grade.

\section{Graphene Oxide Synthesis}

Graphene oxide can be synthesized by i) modified Hummer's method and ii) Improved Hummer's method $[15,16]$. Modified Hummer's method is simple, effective and less time-consuming. Considering these advantages, graphene oxide was synthesized by a modified Hummer's method for our study.

\section{Modified Hummer's Method}

Concentrated sulfuric acid $\left(\mathrm{H}_{2} \mathrm{SO}_{4}\right)$ of $100 \mathrm{ml}$ was added to $2 \mathrm{~g}$ of graphite powder and the mixture was stirred for three hours in a $500 \mathrm{ml}$ round bottom flask maintained at 350 to 450 RPM. Two grams of sodium nitrate was added to the flask and stirred for two hours. Potassium permanganate was added to the mixture at ice bath, which was maintained below $20^{\circ} \mathrm{C}$ and continuously stirred for eight hours at the same RPM. After stirring for eight hours, the color of the solution turned from black to dark green. The ice bath was removed and $200 \mathrm{ml}$ of distilled water was added to the green color solution drop by drop using an addition funnel. The addition of water helps in terminating the reaction followed by the color change from green to brown. After the appearance of the color brown, $150 \mathrm{ml}$ of water was added again continuously to the solution. After one hour of stirring, $15 \mathrm{ml}$ of $30 \%$ hydrogen peroxide $\left(\mathrm{H}_{2} \mathrm{O}_{2}\right)$ was added to the mixture to remove excess potassium permanganate $\left(\mathrm{KMnO}_{4}\right)$. Completion of the reaction was identified by the appearance of a golden yellow color $[17,18]$.

The obtained product was washed five times by using aqueous $\mathrm{HCl}$ solution (1:10) for the removal of unreacted graphite compound. Then the product was washed using distilled water until $\mathrm{pH}$ neutrality was obtained. Particle separation was carried out using a centrifuge working at 4000 RPM. The separated final product was dried at $60^{\circ} \mathrm{C}$ in a hot air oven and ground well.

\section{Preparation of $\mathrm{GO}_{-} \mathrm{TiO}_{2}$ Nanocomposite}

$20 \mathrm{mg}$ of synthesized graphene oxide was added to $100 \mathrm{ml}$ of distilled water and ultrasonically exfoliated in a bath sonicator (citizen digital ultrasonic cleaner) for $30 \mathrm{~min}$ to obtain a light-brown solution. $80 \mathrm{mg}$ of $\mathrm{TiO}_{2}$ was then added to the $\mathrm{GO}$ and stirred for 24 hours using a magnetic stirrer. After completion of the stirring process, the mixture was treated in a sonicator for 30 minutes with the temperature maintained at $45^{\circ} \mathrm{C}$. This mixture was then thoroughly washed with distilled water several times to remove unreacted $\mathrm{TiO}_{2}$ and then 
washed five times again with ethanol. Particle separation was carried out using a centrifuge at 6000 RPM. The final product obtained after particle separation was then vacuum dried at $40^{\circ} \mathrm{C}$ using a desiccator, and the obtained grey colored product obtained is ground well $[13,19]$.

The grey color product thus obtained was thermally treated at $250^{\circ} \mathrm{C}$ for 4 hours using a furnace and then ground into a fine powder. The grey color compound then changes into black color on thermally treated with GO-TiO 2 nanocomposite powder.

\section{Photocatalytic Experiment}

A hexagonal-shaped ultraviolet multi-lamp photoreactor (Heber scientific) with $100 \mathrm{ml}$ capacity made up of borosilicate glass having dimensions $35 \mathrm{~cm} \times 2 \mathrm{~cm}$ (height $\times$ diameter) was used. The experiment was carried out at ambient temperatures. The photocatalytic activity of the photocatalyst was evaluated by decolorizing orange ME2RL. $10 \mathrm{mg}$ of photocatalyst was dispersed into $50 \mathrm{~mL}$ aqueous solution containing $100 \mathrm{mg} / \mathrm{l}$ orange ME2RL dye. The mixture was stirred incessantly using an aerator under UV light. The concentration of Orange ME2RL was measured by using a UV-Vis spectrophotometer at an interval of 5 minutes.

\section{Characterization Methods}

The graphene oxide synthesized by modified Hummer's method and the heat-treated $\mathrm{GO}_{-} \mathrm{TiO}_{2}$ composite were characterized by X-ray diffraction analysis (XRD) for crystalline nature testing, Fourier transform-infrared spectroscopy (FT-IR) for unknown functionality groups determination, scanning electron microscopy (SEM) and HRSEM with EDAX for morphology analysis and weight percentage of materials $\left(\mathrm{GO}-\mathrm{TiO}_{2}\right)$ and UV-DRS analysis for band gap energy determination.

\section{Results and Discussion}

X-ray diffraction analysis was employed to check the crystalline nature of the graphite material. XRD analysis of graphite shows a sharp peak at $26.3^{\circ}$ and interlayer spacing of nanosheets of about $0.334 \mathrm{~nm}$ as shown in Fig. 1(I-a).

The XRD pattern obtained for the synthesized GO nanoparticles by modified Hummer's method is shown in Fig. 1(I-b). The peak generated at $10.22^{\circ}$ represents pure graphene oxide and the inter-layer distance (d-spacing) was calculated to be $0.853 \mathrm{~nm}$. The final product obtained was brown in color when compared to the initial color of graphite, which is black. The synthesized product was confirmed to be graphene oxide by the literature study. Approximately $2.78 \mathrm{~g}$ of
GO was obtained by the modified Hummer's method.

The high angle and the sharp peak as expected for crystalline materials like graphite was obtained as illustrated in Fig. 1 (I-a) and post-treatment, high-angle peak shifted to low-angle peak as can be seen in Fig. 1 (I-b). This graph reveals that graphite was converted to graphene oxide.

The XRD characterization of $\mathrm{TiO}_{2}-\mathrm{GO}$ nanocomposite is shown in Fig. 1(I-c). The anatase $\mathrm{TiO}_{2}$ was obtained regardless of adding graphite oxide at the low preparation temperature. As the calcination temperature increased to $250^{\circ} \mathrm{C}$, the peak at $2 \theta=25.2^{\circ}$ for the graphene oxide- $\mathrm{TiO}_{2}$ samples increased in intensity, as is evident from the sharpening of the peak. This indicates that a higher calcination temperature is favorable for improving the crystallinity of $\mathrm{TiO}_{2}$. These results suggest that the exfoliation of graphite oxide into a single-layer sheet (GO) was successfully achieved [7, 10, 11]. XRD patterns of $\mathrm{GO}^{-\mathrm{TiO}_{2}}$ (Fig. 1(I-c)) suggests the pure anatase phase of $\mathrm{TiO}_{2}$ (JPCDS card: 73-1764).

Fourier transform-infrared spectroscopy (FT-IR) was used to determine the functional group. FT-IR spectrum results for initial graphite and GO are shown in Fig. 1(II-a, b). Fig. 1(II-b) shows that synthesized GO has a peak at $1081 \mathrm{~cm}^{-1}$, which can be attributed to the $\mathrm{C}-\mathrm{O}$ bond, confirming the presence of an oxide functional group after the oxidation process [20]. The $1081 \mathrm{~cm}^{-1}$ peak shows that graphite compound is oxidized successfully. The peaks in the range of $1630 \mathrm{~cm}^{-1}$ to $1650 \mathrm{~cm}^{-1}$ indicated that the $\mathrm{C}=\mathrm{C}$ bond remained before and after the oxidation process. The absorbed water by GO is shown by a broad peak at $2885 \mathrm{~cm}^{-1}$ to $3715 \mathrm{~cm}^{-1}$, contributed by the $\mathrm{O}-\mathrm{H}$ stretch from $\mathrm{H}_{2} \mathrm{O}$ molecules. Fig. 1(II-a) shows the FT-IR result for raw material graphite, where carbonyl or other carbon and oxygen-based functional groups were not present in the material initially. This is supportive of the fact that GO is highly absorptive in nature and later it could be verified by its ability to become a gel-like solution [21].

Scanning electron microscopy (SEM) provides morphology and structure of nanomaterials. Fig. 2a) shows the SEM image of the original graphite. It is apparently about the sheets being stacked together, and Fig. 2b) shows the exfoliated graphene sheet, which confirmed that graphene sheets were exfoliated.

Morphology of the $\mathrm{TiO}_{2}-\mathrm{GO}$ was also analyzed by high-resolution scanning electron microscopy (HRSEM) and EDAX. Fig. 2c) shows HRSEM image for $\mathrm{GO}_{-} \mathrm{TiO}_{2}$ at $5 \mu \mathrm{m}$ magnification. It confirmed the platelets of $\mathrm{GO}^{-} \mathrm{TiO}_{2}$ composites, along with large aggregated $\mathrm{TiO}_{2}$ particles. The picture shows the $\mathrm{TiO}_{2}$ nanoparticles deposited on a single graphene oxide sheet.

EDAX results from Fig. 3a) are given in Table 1, which shows the presence of graphene oxide and titanium dioxide in the prepared nanocomposite. In the nanocomposite, carbon $(\mathrm{C})$, oxygen $\left(\mathrm{O}_{2}\right)$, and 

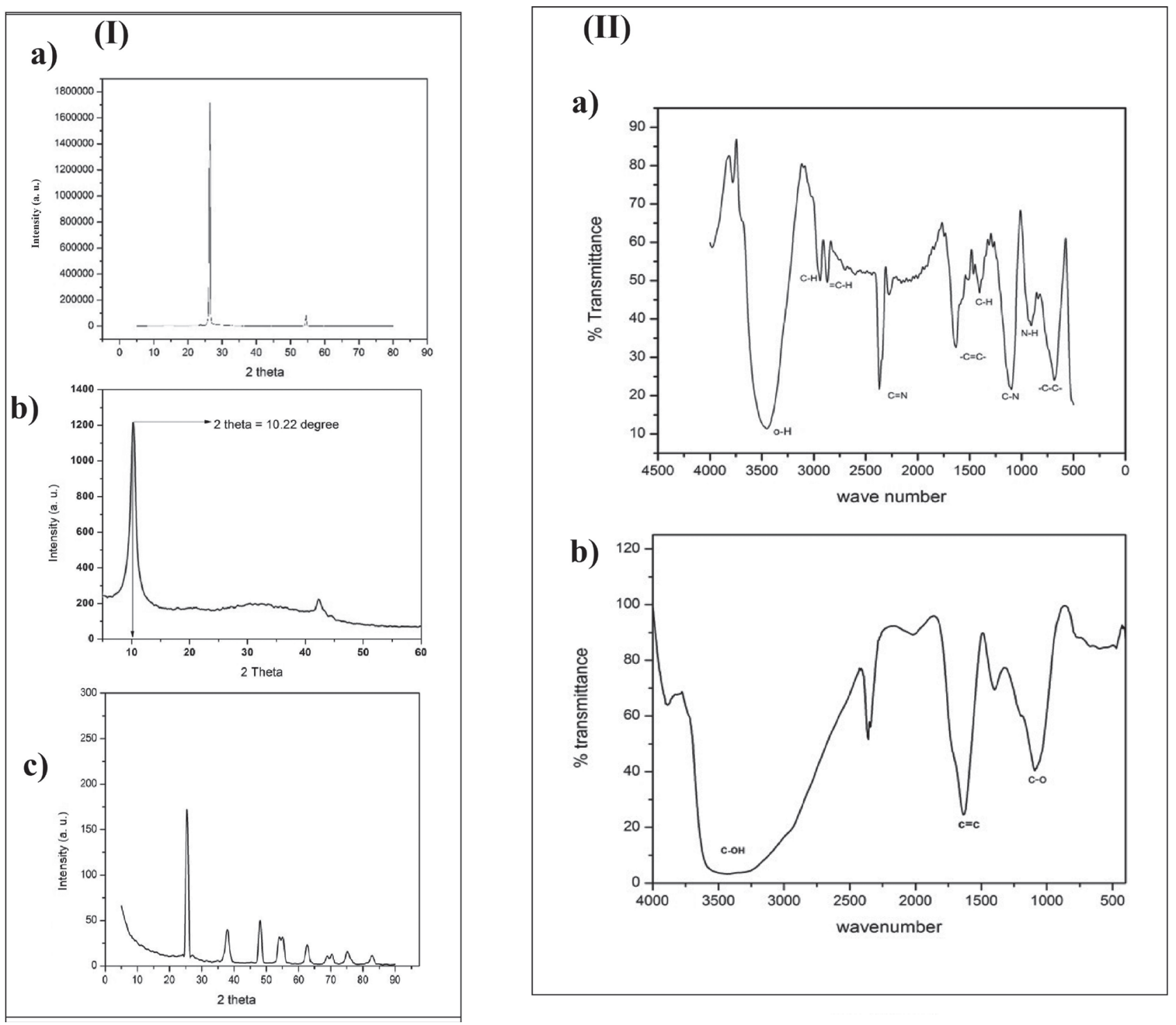

Fig. 1.(I) XRD pattern for a) graphite, b) synthesized graphene oxide (GO), c) $\mathrm{TiO}_{2}-\mathrm{GO}$ nanocomposite; (II) FT-IR spectrum of a) graphite and b) synthesized GO.

titanium (Ti) were present at the $\mathrm{Wt} \%$ respectively of $7.43 \%, 26.53 \%$, and $51.38 \%$. The presence of gold $(\mathrm{Au})$ $14.66 \%$ could be due to gold sputtering of the sample, increasing electrical conductivity [22, 23].
UV-visible diffuse reflectance spectroscopic (UVDRS) analysis is the most widely used technique for determining absorbance, transmittance, and reflectance of powder samples and also used in the bandgap a)

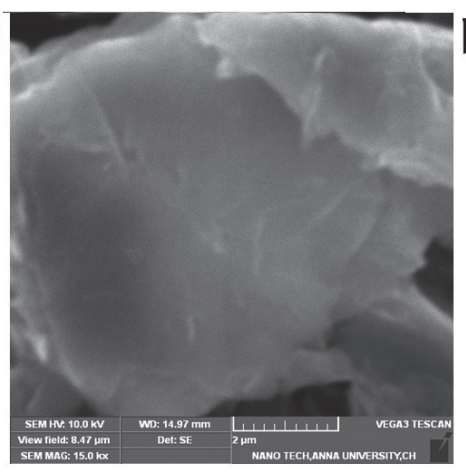

b)

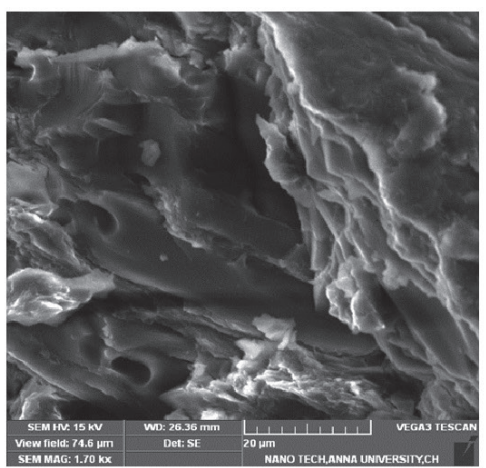

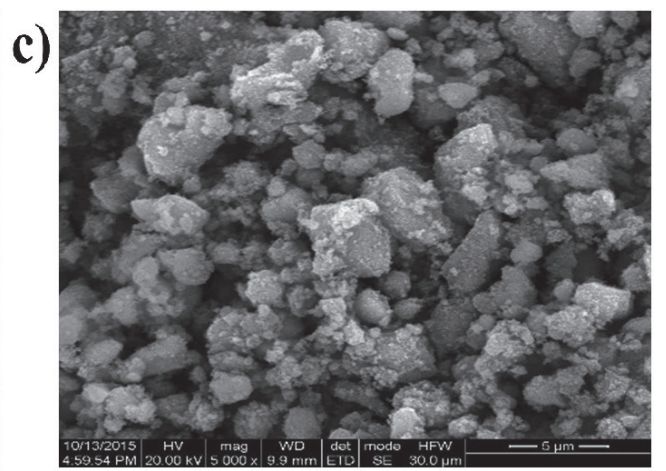

Fig. 2. a) SEM image of raw graphite, b) SEM image of graphene oxide, c) HRSEM image of GO-TiO ${ }_{2}$ composite at $5 \mu \mathrm{m}$. 
Table 1. Weight percentage of elements in nanocomposite.

\begin{tabular}{|c|c|}
\hline Element & $\mathrm{Wt} \%$ \\
\hline Carbon $(\mathrm{C})$ & 07.43 \\
\hline Oxygen $(\mathrm{O})$ & 26.53 \\
\hline Titanium $(\mathrm{Ti})$ & 51.38 \\
\hline
\end{tabular}
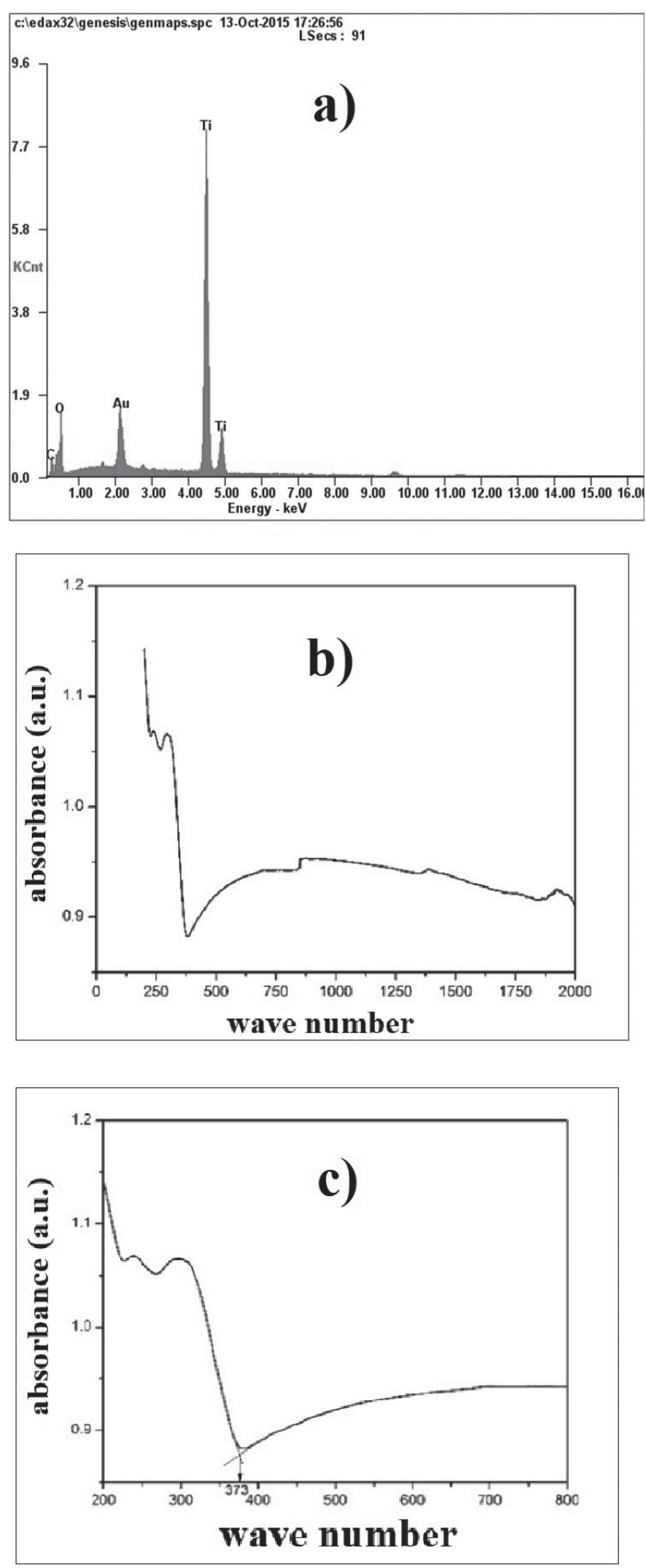

Fig. 3. a) EDAX graph of nanocomposite, UV- DRS analysis for b) $\mathrm{GO}-\mathrm{TiO}_{2}$ nanocomposite, c) cut-off wavelength. calculation of the sample. UV-DRS analysis result of the GO-TiO 2 nanocomposite is shown in Fig. 3 (b) and (c).

\section{Band Gap Energy for GO-TiO}

The band gap energy is the smallest energy difference between the valence band and the conduction band. If a wide-band gap semiconductor like titanium dioxide is irradiated with light, excited electron-hole pairs result in chemical processes and can be employed in degradation of compounds by processes like photocatalysis. The performance of a photocatalyst under light irradiation depends mainly on band gap energy and light radiation, which must be sufficient to form electron-hole pairs. Band gap energy was calculated by the Planks-Einstein equation:

$$
E=\frac{h^{*} c}{\lambda}
$$

...where ' $\mathrm{E}$ ' is band gap energy, ' $\mathrm{h}$ ' is Planks constant, ' $c$ ' is the speed of light and ' $\lambda$ ' the cutoff wavelength; and for $\mathrm{GO}-\mathrm{TiO}_{2}$ nanocomposite, which was calculated from UV-DRS data as $\lambda=373 \mathrm{~nm}$, which is shown in Fig. 3(c).

By using the formula, band gap energy has been calculated as $3.32 \mathrm{eV}$. It can be found that $\mathrm{GO}-\mathrm{TiO}_{2}$ composites do not show obvious band gap energy narrowing [13]. The wide spectral range response of light source can be used more efficiently for the narrow band gap. The wide band gap confirmed that the prepared photocatalyst will perform better in a UV range of light source.

\section{Removal of ORANGE ME2RL by Photocatalysis Using Synthesized GO-TiO,}

\section{Effect of Time}

The relationship between the percentage removal of the dye and irradiation time is shown in Fig. 4a). It is clearly seen that the rate of degradation increases with increases in irradiation time. Fig. 4a) shows that the percentage of degradation increases with increasing irradiation time at the constant dye concentration, catalyst dosage, and $\mathrm{pH}$ of $100 \mathrm{mg} / \mathrm{L}, 10 \mathrm{mg} / \mathrm{ml}$, and $5.5 \mathrm{pH}$ respectively. Irradiation time was studied between $2 \mathrm{~min}$ to $30 \mathrm{~min}$. It can be observed that the maximum dye degradation of $99.65 \%$ can be achieved after 24 minutes of complete irradiation. This is because of the reason that when time increases, the chance of contact increases between dye and catalyst.

\section{Effect of Dye Concentration}

The effect of dye degradation has been studied at a constant dye concentration of $10 \mathrm{mg} / 1$ to $100 \mathrm{mg} / \mathrm{l}$, at the catalyst dosage of $10 \mathrm{mg} / 50 \mathrm{ml}, 5.5 \mathrm{pH}$ and constant time 10 minutes. Percentage degradation decreases 

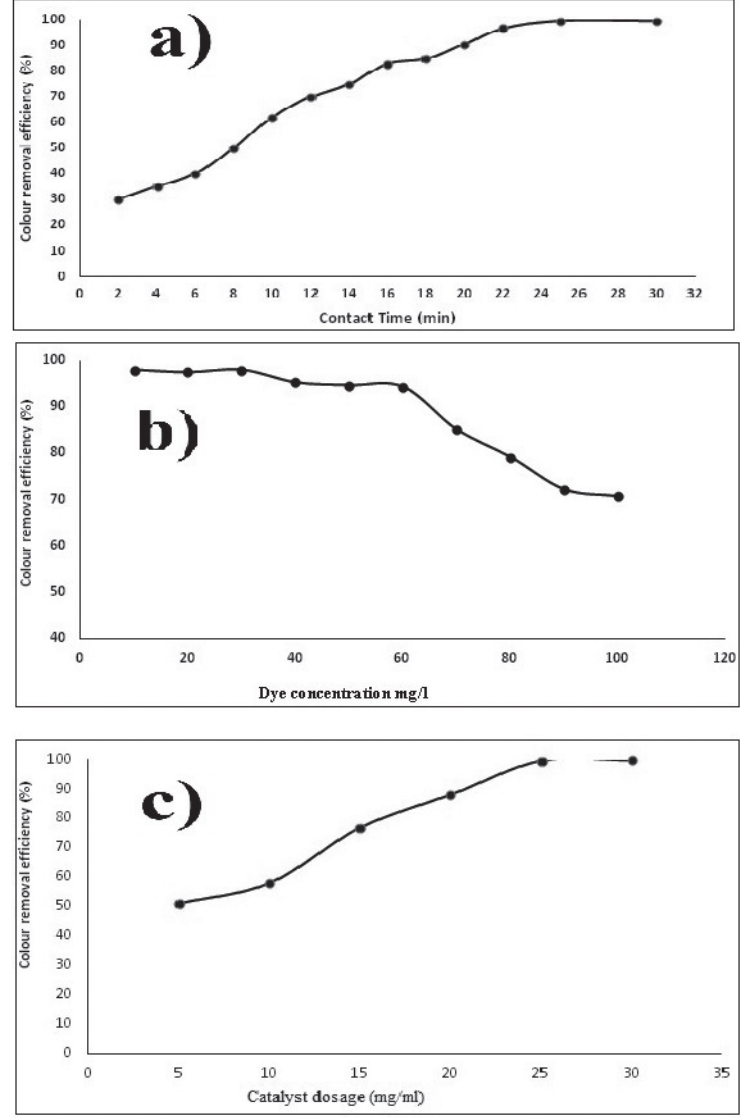

Fig. 4. a) Effect of time on dye degradation process, b) effect of dye concentration on dye degradation process, c) effect of catalyst dosage on color removal.

with increasing dye concentration, which is shown in Fig. 4b). This may be because, with increasing concentration, the number of active sites available on the catalyst becomes insufficient.

\section{Effect of Catalyst Dosage}

The effect of catalyst dosage on color removal from wastewater using Orange ME2RL dye was studied by varying the dosage of catalyst between $5 \mathrm{mg}$ to $30 \mathrm{mg}$ at constant $\mathrm{pH}$ of 5.5, 10 minutes contact time and $100 \mathrm{mg} / \mathrm{L}$ dye concentration. The relationship between the percentage removal of color and catalyst dosage is shown in Fig. 4c). It shows that the percentage of color removal increases with increasing catalyst dosage. It may be that with an increase in catalyst dosage, the number of active sites increases. Subsequently, the color removal percentage increases from $51 \%$ to $99.62 \%$ with the maximum percentage of color removal, using $25 \mathrm{mg}$ of catalyst.

\section{Effect of $p H$}

Point of zero charge $\left(\mathrm{pH}_{\mathrm{ZPC}}\right)$ is one of the important parameter of a photocatalyst. When the $\mathrm{pH}$ value of
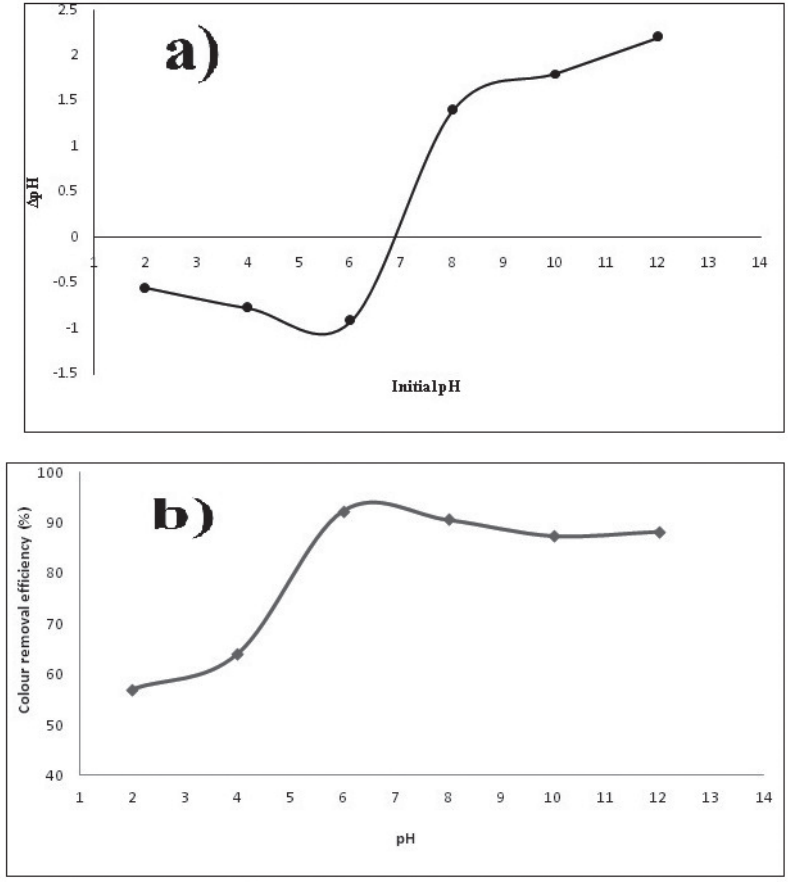

Fig. 5. a) $\mathrm{pH}$ of the point of zero charges of photocatalyst (GO$\mathrm{TiO}_{2}$ ), b) effect of $\mathrm{pH}$ in color removal.

the solution is higher than $\mathrm{pH}_{\mathrm{ZPC}}$, the surface of the photocatalyst becomes negatively charged and favours the adsorbtion of positively charged particles. In the same way, the photocatalyst will favour the adsorption of negatively charged particles in the solution with $\mathrm{pH}$ lower than the $\mathrm{pH}_{\mathrm{ZPC}}$. The $\mathrm{pH}$ at the point of zero charges $\left(\mathrm{pH}_{\mathrm{ZPC}}\right)$ means the surface of adsorbent is neutral, i.e., it contains as much positively charged as negatively charged. $\mathrm{pH}_{\mathrm{ZPC}}$ is calculated to find the favorable conditions of the process. Surface functions were studied by taking $50 \mathrm{~mL}$ of $0.01 \mathrm{M} \mathrm{NaCl}$ solutions in differently closed Erlenmeyer flasks [24]. The $\mathrm{pH}$ of the solution in each flask was adjusted to values of 2, 4, 6, 8, 10 and 12 by adding $0.1 \mathrm{M} \mathrm{HCl}$ or $0.1 \mathrm{M} \mathrm{NaOH}$ solutions. Then $0.15 \mathrm{~g}$ of catalyst was added to each flask, agitated in a shaker and allowed to stay for $48 \mathrm{hrs}$. The final supernatant $\mathrm{pH}$ value $\left(\mathrm{pH}_{\mathrm{f}}\right)$ was noted. The difference between initial and final $\mathrm{pH}$ value $\left(\Delta \mathrm{pH}=\mathrm{pH}_{\text {initial }}-\mathrm{pH}_{\text {final }}\right)$ was plotted against $\mathrm{pH}_{\text {initial. }}$. The point of intersection of the resulting curve at with $\Delta \mathrm{pH}=0$ gives the value of $\mathrm{pH}_{\mathrm{ZPC}}$. Fig. 5a) shows that $\mathrm{pH}$ at the point of zero charges for the photocatalyst, $\mathrm{GO}^{-\mathrm{TiO}_{2}}$. pH at the point of zero charges was determined as $6.8\left(\mathrm{pH}_{\mathrm{ZPC}}=6.8\right)$.

Below $\mathrm{pH}_{\mathrm{ZPC}}$, i.e., $6.8 \mathrm{pH}$, the surface of $\mathrm{GO}^{-\mathrm{TiO}_{2}}$ nano composite become positively charged, resulting in the higher attraction of our anionic dye solution, and at $\mathrm{pH}$ values above 6.8 , the percentage color removal will decrease for our negatively charged dye solution. $\mathrm{A} \mathrm{pH}$ value less than the value of $\mathrm{pH}_{\mathrm{ZPC}}$ is a favorable condition as the number of positively charged sites increases and favors the adsorption of negatively charged dye ions because of the electrostatic force of attraction and color 


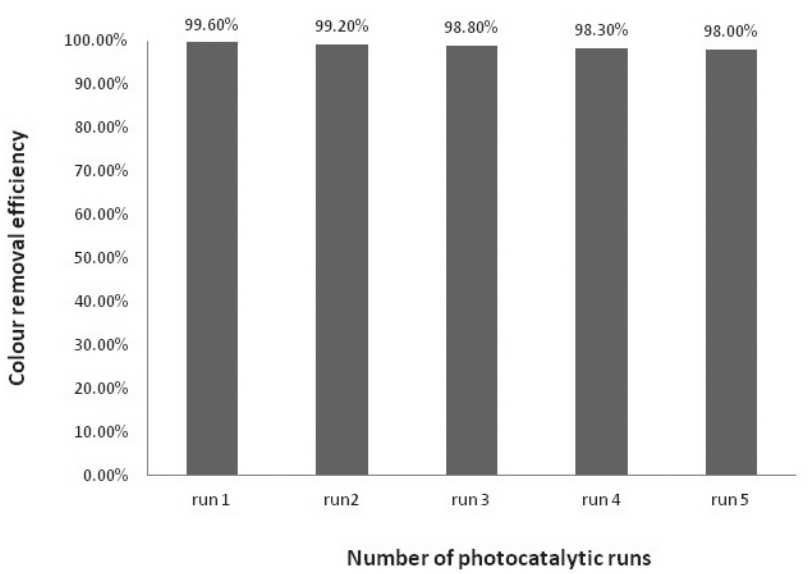

Fig. 6. Efficiency on re-usage of photocatalyst $\mathrm{GO}^{-\mathrm{TiO}_{2}}$ nanocomposite.

removal $92.36 \%$ for synthetic dye solution was achieved at $\mathrm{pH}$ 6, which is shown in Fig. 5b) [24].

\section{Recovery and Reuse of the Photocatalyst $\mathrm{GO}-\mathrm{TiO}_{2}$}

The used photocatalyst (GO-TiO 2 nanocomposite) was recovered by using centrifugation. Then the recovered catalyst was washed several times by using ethanol and distilled water and then the recovered nanocomposite was again subjected to photocatalytic experiment. This process was continued for several numbers of run at constant $\mathrm{pH} 5.5$, contact time 10 minutes, catalyst dosage $10 \mathrm{mg} / \mathrm{mL}$ and dye concentration $100 \mathrm{mg} / \mathrm{L}$. The results obtained are shown in Fig. 6 mapping number of runs with the percentage color removal of Orange ME2RL dye. From Fig. 6 it can be observed that there is no significant decrease in the photocatalytic activity of photocatalyst, $\mathrm{GO}_{-} \mathrm{TiO}_{2}$. Even after 5 runs, the color removal percentage of Orange ME2RL dye was around 98\%, which reveals that the photocatalyst $\mathrm{GO}^{-}-\mathrm{TiO}_{2}$ has high stability and can be reused for real-time applications.

\section{Conclusions}

Graphene oxide was successfully synthesized from graphite powder by modified Hummer's method. GO-TiO ${ }_{2}$ nanocomposite was also successfully prepared by using the ultra-sonication method. Characterization studies for both $\mathrm{GO}$ and $\mathrm{GO}_{-} \mathrm{TiO}_{2}$ nanocomposite were done by XRD for determining crystalline nature; FTIR for determination of unknown functional groups; SEM and TEM for morphology test; EDAX test for calculating the percentage of materials present in the compound and UV-DRS analysis for the determination of band gap energy and photocatalytic ability.

The synthesized nanocomposite was employed as a catalyst to remove Orange ME2RL organic dye from synthetic wastewater by photocatalysis and also the parameters $\mathrm{pH}$, contact time, dye concentration, and catalyst dosage were varied and found that the highest color removal for $60 \mathrm{mg} / \mathrm{l}$ dye concentration was obtained at a catalyst dosage of $25 \mathrm{mg}$ with contact time of 24 minutes and at a $\mathrm{pH}$ value of 6 . The catalyst stability and reusability were studied. The color removal efficiency of the catalyst was found as 99.6, 99.2, 98.8, 98.3 and 98 percentages for the $1^{\text {st }}, 2^{\text {nd }}, 3^{\text {rd }}, 4^{\text {th }}$ and $5^{\text {th }}$ cycles on reusing the catalyst. These studies conclude that the catalyst can be used for real-time applications.

\section{Acknowledgements}

We thank the members of the Effluent Treatment Laboratory, Department of Chemical Engineering, Anna University, for their support through this present work.

\section{Conflict of Interest}

The authors declare no conflict of interest.

\section{References}

1. AGUEDACH A., BROSILlON S., MORVAN J., LHADI E.K. Photocatalytic degradation of azo-dyes reactive black 5 and reactive yellow 145 in water over a newly deposited titanium dioxide. Applied Catalysis B: Environmental, 57 (1), 55, 2005.

2. SAKTHIVEL S., NEPPOLIAN B., SHANKAR M.V., ARABINDOO B., PALANICHAMY M., MURUGESAN V. Solar photocatalytic degradation of azo dye: Comparison of photocatalytic efficiency of $\mathrm{ZnO}$ and $\mathrm{TiO}_{2}$. Solar Energy Materials and Solar Cells, 77 (1), 65, 2003.

3. PATIL V.B. A comparative study on photo degradation of methylene blue dye effluent by advanced oxidation process by using $\mathrm{TiO}_{2} / \mathrm{ZnO}$ photo catalyst. Rasayan Journal, 4 (4), 814, 2011.

4. GÜL Ş., ÖZCAN Ö., ERBATUR O. Ozonation of C.I. Reactive Red 194 and C.I. Reactive Yellow 145 in aqueous solution in the presence of granular activated carbon. Dyes and Pigments, 75 (2), 426, 2007.

5. NEPPOLIAN B., CHOI H.C., SAKTHIVEL S., ARABINDOO B., MURUGESAN V. Solar/UV-induced photocatalytic degradation of three commercial textile dyes. Journal of Hazardous Materials, 89 (2), 303, 2002.

6. ŠÍMA J., HASAL P. Photocatalytic degradation of textile dyes in $\mathrm{aTiO}_{2}$-UV system. Chemical Engineering Transactions, 32 (1999), 79, 2013.

7. ZHANG Y., PAN C. $\mathrm{TiO}_{2}$ /graphene composite from thermal reaction of graphene oxide and its photocatalytic activity in visible light. Journal of Materials Science, 46 (8), 2622, 2011.

8. DONG S., DOU X., MOHAN D., PITTMAN C.U., LUO J. Synthesis of graphene oxide/schwertmannite nanocomposites and their application in $\mathrm{Sb}(\mathrm{V})$ adsorption from water. Chemical Engineering Journal, 270 (06), 205, 2015.

9. DUBEY S.P., NGUYEN T.T.M., KWON Y.N., LEE C. Synthesis and characterization of metal-doped reduced 
graphene oxide composites, and their application in removal of Escherichia coli, arsenic and 4-nitrophenol. Journal of Industrial and Engineering Chemistry, 29, 282, 2015.

10. PHAM T.T., NGUYEN-HUY C., LEE H.J., NGUYENPHAN T.D., SON T.H., KIM C.K., SHIN E.W. Cu-doped $\mathrm{TiO}_{2} /$ reduced graphene oxide thin-film photocatalysts: Effect of $\mathrm{Cu}$ content upon methylene blue removal in water. Ceramics International, 41 (9), 11184, 2015.

11. CAO S., CHEN C., LIU T., ZENG B., NING X., CHEN, X., CHEN, W. Superfine and closely-packed $\mathrm{TiO}_{2} /$ $\mathrm{Bi}_{2} \mathrm{O}_{3}$ lamination on graphene nanoplates with high photocatalytic activity. Catalysis Communications, 46, 61, 2014.

12. JIANG G., LIN Z., CHEN C., ZHU L., CHANG Q., WANG N., TANG $\mathrm{H}$. $\mathrm{TiO}_{2}$ nanoparticles assembled on graphene oxide nanosheets with high photocatalytic activity for removal of pollutants. Carbon, 49 (8), 2693, 2011.

13. CHEN C., CAI W., LONG M., ZHOU B., WU Y., WU D., FENG Y. Synthesis of visible-light responsive graphene oxide/ $\mathrm{TiO}_{2}$ composites with $\mathrm{p} / \mathrm{n}$ heterojunction. ACS Nano, 4 (11), 6425, 2010.

14. ISMAIL N., MADIAN M., EL-SHALL M.S. Reduced graphene oxide doped with $\mathrm{Ni} / \mathrm{Pd}$ nanoparticles for hydrogen storage application. Journal of Industrial and Engineering Chemistry, 30 (6), 328, 2015.

15. MARCANO D. C., KOSYNKIN D.V., BERLIN J.M., SINITSKII A., SUN Z., SLESAREV A., TOUR J.M. Improved synthesis of graphene oxide. ACS Nano, 4 (8), 4806, 2010.

16. CARMEN Z., DANIEL S. Textile Organic Dyes Characteristics, Polluting Effects and Separation/ Elimination Procedures from Industrial Effluents - A Critical Overview. In Organic Pollutants Ten Years After the Stockholm Convention - Environmental and Analytical Update (pp. 55-86). InTech. 2012.
17. ZHANG M., LI R., CHANG X., XUE C., GOU X. Hybrid of porous cobalt oxide nanospheres and nitrogen-doped graphene for applications in lithium-ion batteries and oxygen reduction reaction. Journal of Power Sources, 290, 25, 2015.

18. LI R., WEI Z., GOU X., XU W. Phosphorus-doped graphene nanosheets as efficient metal-free oxygen reduction electrocatalysts. RSC Advances, 3 (25), 9978, 2013.

19. JIANG G., LIN Z., CHEN C., ZHU L., CHANG Q., WANG N., TANG $\mathrm{H}$. $\mathrm{TiO}_{2}$ nanoparticles assembled on graphene oxide nanosheets with high photocatalytic activity for removal of pollutants. Carbon, 49 (8), 2693, 2011.

20. MELO J.P., RÍOS P.L., POVEA P., MORALES-VERDEJO C., CAMARADA M.B. Graphene Oxide Quantum Dots as the Support for the Synthesis of Gold Nanoparticles and Their Applications as New Catalysts for the Decomposition of Composite Solid Propellants. ACS Omega, 3 (7), 7278, 2018.

21. ARTHI G.P.B., BD L. A Simple Approach to Stepwise Synthesis of Graphene Oxide Nanomaterial. Journal of Nanomedicine \& Nanotechnology, 6 (1), 2, 2015.

22. BASHEER C. Application of titanium dioxide-graphene composite material for photocatalytic degradation of alkylphenols. Journal of Chemistry, 2012 (8), 1, 2013.

23. PARK C., GHOSH T., MENG Z., KEFAYAT U., VIKRAM N., OH W. Preparation of CuS-graphene oxide/ $\mathrm{TiO}_{2}$ composites designed for high photonic effect and photocatalytic activity under visible light. Chinese Journal of Catalysis, 34 (4), 711, 2013.

24. BANERJEE S., CHATTOPADHYAYA M.C. Adsorption characteristics for the removal of a toxic dye, tartrazine from aqueous solutions by a low cost agricultural byproduct. Arabian Journal of Chemistry, 10 (5), S1629, 2017. 